\title{
Dossî́
}

\section{Ciência da Religião e Ciência da Religião Aplicada à educação: formação de professores e Ensino Religioso}

RODRIGO Oliveira dos SANTOS ${ }^{1}$

Resumo: A Ciência da Religião é uma disciplina acadêmica que vem se consolidando enquanto ciência de referência para a formação de professores de Ensino Religioso, assim como para a sua aplicação nas escolas públicas e privadas. Esse avanço na educação brasileira - talvez possa ser considerado o maior no mundo - conta com o novo ramo ou desdobramento dessa disciplina, a Ciência da Religião Aplicada, que viabiliza em nível cognitivo os conhecimentos produzidos na Ciência da Religião, funcionando como mediadores e viabilizadores no estudo sobre religiões em relação aos desafios que emergem desse objeto na sociedade.

Palavras-chave: Ciência da religião. Ciência da religião aplicada. Formação de professores. Ensino religioso.

\section{Science of Religion and Science of Religion Applied to education: teacher training and Religious Teaching}

\begin{abstract}
The Science of Religion is an academic discipline that has been consolidating as a reference science for the training of teachers of Religious Education, as well as for its application in public and private schools. This advance in Brazilian education may be considered the greatest in the world. It has the new branch or division of this discipline, the Science of Applied Religion, which enables the knowledge produced in the Science of Religion to function cognitively, functioning as mediators and enablers in study of religions in face of the challenges that emerge from this object in society.

Keywords: Science of religion. Science of applied religion. Teacher training. Religious education.
\end{abstract}

Ciencia de la Religión y Ciencia de la Religión Aplicada a la educación: formación de profesores y Educación Religiosa

Resumen: La Ciencia de la Religión es una disciplina académica que viene consolidándose como ciencia de referencia para la formación de profesores de Educación Religiosa, así como para su aplicación en las escuelas públicas y también privadas. Este avance en la educación brasileña, tal vez pueda ser considerado el más grande en el mundo, cuenta con una nueva rama o desdoblamiento de esa disciplina, la Ciencia de la Religión 
Aplicada, que viabiliza a nivel cognitivo los conocimientos producidos en la Ciencia de la Religión, funcionando como mediadores y viabilizadores estudio sobre religiones frente a los desafíos que emergen de este objeto en la sociedad.

Palabras clave: Ciencia de la religión. Ciencia de la religión aplicada. Formación de profesores. Educación religiosa.

Ninguém escapa da educação. Em casa, na rua, na igreja ou na escola, de um modo ou de muitos, todos nós envolvemos pedaços da vida com ela: para aprender, para ensinar, para aprender-e-ensinar.

Para saber, para fazer, para ser ou para conviver, todos os dias misturamos a vida com a educação. Brandão (2007, p. 7)

\section{Introdução}

Os primeiros registros da Ciência da Religião (CR) no Brasil datam da segunda metade do século XX, inicialmente ocupando o mesmo espaço que a Teologia, da qual foi se desvinculando gradativamente, mas não o suficiente como no contexto internacional em que apresenta maior prestígio acadêmico-cultural e social.

Essa apreensão poderia até ser considerada de certa forma precipitada, principalmente por aqueles que se apropriaram do estudo sobre religiões no Brasil, espaço acadêmico e sociocultural fortemente marcado pela tradição judaico-cristã católica que, nesse último século e início deste milênio, sofre com o impacto político-simbólico do cristianismo evangélico.

Em outras palavras, as religiões cristãs sempre impactaram de diversas formas a esfera pública e social latino-americana. No caso brasileiro, esse aspecto é surpreendentemente significativo para a compreensão e a interpretação das dinâmicas relacionais sociopolíticas e culturais, agindo, de alguma forma, na produção e na disseminação do conhecimento, especialmente no campo educacional.

Nesse aspecto, pensar a Ciência da Religião Aplicada (CRA) ao campo educacional brasileiro, a princípio, é se confrontar com a proposta educacional colonial, imperial e republicana que recentemente vem tentando afastar da esfera pública e social as determinações e influências religiosas, ora com sucesso, ora com ressalvas, pois "ninguém escapa da educação" (BRANDÃO, 2007, p. 7). Nesse caso, ninguém escapou da educação católica, presente e imposta durante séculos no Brasil.

O esforço empreendido na desconfessionalização da educação, especialmente no currículo da Educação Básica (EB), não está apenas restrito ao Ensino Religioso (ER), como muitos equivocadamente pensam. Esse aspecto está presente em outras áreas de conhecimento e componentes curriculares. Seu teor, provavelmente, não venha sendo exposto por seus executores com os confron- 
tos e os esclarecimentos necessários para ser discernido e aplicado durante a sua formação inicial; assim, não há separação entre o privado e o público, o pessoal e o coletivo, o sobre-humano e o humano.

Um grande exemplo disso pode ser observado no curso de Pedagogia, cujas abordagens e intervenções pedagógicas, ora seja na gestão, ora na coordenação, muitas vezes ainda são marcadas pelos recursos religiosos cristãos; essa apreensão tem sido confirmada por meio da atuação profissional do autor deste artigo no Ensino Superior e no Ensino Básico.

Não é preciso ir muito longe. Os próprios centros formadores acabam reproduzindo visões e comportamentos religiosos pessoais ou dominantes, evidenciando uma questão muito presente na CR que suscitam as seguintes indagações: quem foram os formadores dos formadores desses professores? Qual foi a sua formação inicial? Quais foram as bases e as abordagens epistemológicas consideradas na sua formação inicial, continuada e profissionalização? Quais e como foram suas experiências na EB?

Dessa forma, a CR cumpre um papel primordial para a educação formal, pública e laica com o estudo sobre religiões em toda sua abrangência, sua influência e suas determinações, considerando seu ideal de neutralidade, com base no agnosticismo metodológico em que não são questionadas as suas verdades nem qualidades, pois, "do ponto de vista metodológico, religiões são 'sistemas de sentido formalmente idênticos'. É especificadamente esse princípio metateórico que distingue a Ciência da Religião da Teologia” (USARSKI, 2006, p. 126).

É esse princípio metateórico que torna possível e pertinente no currículo escolar o ER transmutado a partir dos resultados das pesquisas desenvolvidas na $\mathrm{CR}$, especialmente pela CRA, por intermédio de desdobramento prático e aplicado da disciplina para resolução de problemas e demandas da sociedade. No Brasil, isso ainda é recente, mas o cenário mundial já conta com algumas produções teóricas, especialmente na Alemanha.

Nesse sentido, a CRA é uma ramificação ou um desdobramento dessa disciplina acadêmica, que tem, nesse profissional da educação e no ER, os seus resultados aplicados, a saber: da resolução e mediação de problemas antigos e ainda impactantes na sociedade, como intolerância religiosa, fundamentalismos e conflitos religiosos e tantas outras formas de violências originadas e motivadas pela falta de conhecimento sistemático, crítico, ético e reflexivo sobre religiões.

\section{A Ciência da Religião}

A Ciência da Religião, em alemão Religionswissenschaft, é uma disciplina acadêmica surgida na segunda metade do século XIX com o indólogo e filólogo alemão Friedrich Max Müller (1823-1900), professor na Universidade de Oxford desde 1954 (GRESCHAT, 2005; USARSKI, 2006, 2013). 
Friedrich Max Müller desenvolveu um papel central para essa nova disciplina que se estabeleceu no espaço acadêmico ao lado da Sociologia, Psicologia, Antropologia, Etnologia, História, dentre outras que compõem o leque das Ciências Humanas e Sociais, que foram fortemente marcadas epistemologicamente pelas Ciências Naturais no século XIX, período de surgimento e institucionalização dessas ciências.

Nesse aspecto, entre o surgimento e a institucionalização da disciplina ainda no século XIX, destacaram-se também de forma tão significativa quanto Müller, a partir de 1877, os professores holandeses Cornelius Petrus Tiele (1830-1902), na Universidade de Leiden, e Pierre Daniël Chantepie de la Saussaye (1848-1920), na Universidade de Amsterdã, compondo a tríade formadora de pais da CR (USARSKI, 2006; COSTA; STERN, 2017).

Outro teórico a se destacar, segundo Greschat (2005, p. 47), foi Joachim Wach com sua tese de livre-docência enfatizando que "a Ciência da Religião estabeleceu-se sobre duas bases. Uma delas é a 'história da religião', a outra a 'história comparada da religião', a que alguns preferem chamar 'Fenomenologia da Religião' e, outros, 'Ciência Sistemática da Religião"'.

A história da religião, ainda segundo o autor, aponta para uma abordagem específica, singular, longitudinal ou particular realizado dentro de uma religião, enquanto a história comparada da religião se detém em uma abordagem mais geral, plural e transversal de várias religiões, a fim de estudar um traço comum, universal.

De uma forma ou de outra, o cientista das religiões está envolvido com ambas as abordagens na sua prática acadêmica e profissional, seja ela singular, seja ela plural, pois:

O objetivo da Ciência da Religião é fazer um inventário, o mais abrangente possível, de fatos reais do mundo religioso, um entendimento histórico do surgimento e desenvolvimento de religiões particulares, uma identificação e seus contatos mútuos, e a investigação de suas inter-relações com outras áreas da vida. A partir de um estudo de fenômenos religiosos concretos, o material é exposto à análise comparada. Isso leva ao entendimento das semelhanças e diferenças de religiões singulares a respeito de suas formas, conteúdos e práticas. O reconhecimento de traços comuns do cientista da religião permite deduzir elementos que caracterizam a religião em geral, ou seja, como um fenômeno antropológico universal (USARSKI, 2006, p. 126-127).

A forma de lidar com esses fenômenos permite a abordagem das religiões nos diferentes espaços, inclusive os públicos, pois, ao analisar as religiões como um fenômeno antropológico universal, ao mesmo tempo busca responder às demandas 
específicas que nenhuma disciplina específica pode oferecer, em função da sua dupla estrutura em estudos históricos e sistemáticos das religiões (USARSKI, 2013).

Nesse aspecto, "o status institucional da disciplina é, em parte, fruto de uma demanda pública no sentido da relevância prático-social da disciplina que, por sua vez, sanciona o apoio político e material da disciplina por órgãos públicos" (USARSKI, 2013, p. 51). Essas demandas podem ser reconhecidas em diferentes setores e instituições públicas e privadas, como está em destaque na reflexão de Brandão (2007), citada no início do texto: quem escapa da educação, ou melhor, da religião?

Por causa de vários fatores que mudaram profundamente as relações e os comportamentos humanos nesses últimos dois séculos de Ciências Humanas, bem como em razão da necessidade e da urgência na atuação diante dos desafios e dos obstáculos que emergem a todo tempo, a demanda religião continua se destacando; daí o surgimento de questões bioéticas, de gênero, étnico-raciais, de diversidade sexual, ambiental, econômica, política, entre outras, que estão fortemente ligadas às religiões, especialmente quando chega à educação e à escola, sendo a primeira vista como um campo de definição e conflitos de políticas pelo Estado, legislador e responsável por ela, enquanto a segunda é vista como o espaço privilegiado para aplicação do que foi definido, normatizado, organizado e determinado pela primeira.

Nesses termos, a CR vem se destacando no Brasil com as experiências em licenciaturas, que habilitam profissionalmente professores para a docência no ER, nos mesmos termos legais previstos para as outras áreas/componentes curriculares da EB, produzindo ganhos significativos para a educação e a escola no que se refere à formação humana, ao lado dos outros componentes curriculares.

Recentemente, também se buscam estabelecer discussões epistemológicas sobre o caráter mais prático ou aplicado da CR no Brasil, algo que vai se iniciar nesta década, principalmente com a publicação do Compêndio de Ciência da Religião (PASSOS; USARSKI, 2013).

Dessa forma, procurou-se discutir brevemente sobre esse caráter prático e aplicado da CR, relacionando-a com o contexto educacional e considerando as contribuições das licenciaturas em CR que produzem um cenário favorável para o estudo sobre religiões nas escolas públicas.

\section{Ciência da Religião Aplicada}

A Ciência Prática da Religião (CPR), ou ainda Ciência da Religião Engajada ou Ciência da Religião Aplicada (CRA), já era algo que permeava o pensamento de Max Müller e de outros estudiosos das religiões que, ao mesmo tempo que rejeitavam esse desdobramento da $\mathrm{CR}$, defendiam que ele deveria ser executado por outros especialistas também das religiões (TWORUSCHKA, 2013). 
De qualquer forma, esse desdobramento interno da disciplina, outrora constatado por Müller, foi ganhando corpo teórico-metodológico e, atualmente, tem como seu principal representante o professor emérito do Departamento de CR da Universidade de Jena, na Alemanha, Udo Tworuschka.

Tworuschka (2013) prefere utilizar o termo CPR para a distinção característica da ciência iluminista em pura e aplicada, ou seja, "a ciência pura é caracterizada pelo seu interesse exclusivo no conhecimento, ao passo que as ciências aplicadas estão interessadas em desenvolver normas, modelos e procedimentos para uma 'prática baseada na ciência"' (TWORUSCHKA, 2013, p. 578). Os termos "puro" e "aplicado" (prático) são uma delimitação que ganhou força durante o Iluminismo, movimento filosófico-científico que se destacou durante o século XVIII na Europa.

$\mathrm{O}$ autor se refere ao químico sueco Johan Wallerius, que demonstrou o significado da aplicação da sua ciência para usos industriais. Esse aspecto, que caracteriza e ao mesmo tempo distingue o puro do prático, aponta que esses termos são indissociáveis, pois, enquanto a ciência pura se ocupa das descobertas dos fatos, a ciência aplicada consiste na sua utilização. Em linhas gerais, o prático utilizado por Tworuschka (2013) equivale ao aplicado para os professores, sendo o último o que melhor traduz a utilização das descobertas pela ciência pura.

Dessa forma, a CRA, termo utilizado no texto, “[...] se refere a um modelo de Ciência da Religião ilimitado, inter e transdisciplinar, que incentiva e promove uma ação orientada, crítica, comunicativa, político-social da Ciência da Religião" (TWORUSCHKA, 2013, p. 579).

Além disso, segundo o autor, a CRA “direciona a atenção do pesquisador para a percepção de indivíduos religiosos e seus modos específicos de percepção, bem como para a percepção de diversas religiões vivas no "mundo vivo" (TWORUSCHKA, 2013, p. 579), em um constante aprendizado comunicativo, permitindo o diálogo entre diferentes experiências religiosas e, consequentemente, a compreensão de horizontes diferenciados.

Para isso, dialoga epistemologicamente com outras disciplinas das Ciências Humanas (Psicologia, Sociologia, História, Fenomenologia, Educação, Antropologia, Política, Geografia, Artes, Filosofia, Etnometodologia etc.) e outros campos de estudos, tendo em vista a sua aplicabilidade em realidades presentes e problemáticas, da qual intermedeia processos diplomáticos e humanitários, no sentido de contribuir com realidades futuras melhores.

Em suma, a CRA, como novo desdobramento da CR, é uma ciência pacificadora, humanizadora e conciliadora que promove "ações úteis e utilizáveis respaldadas cientificamente e aplicadas a realidades diferenciadas, tornando-as mais viáveis e justificáveis para a sobrevivência humana” (TWORUSCHKA, 2013, p. 579). 
Dessa forma, a CRA foi se constituindo no espaço acadêmico, contando, para isso, segundo Tworuschka (2013), com as contribuições teóricas de Gustav Mensching (1901-1978), Hans-Joachim Klimkeit (1939-1999), Mircea Eliade (1907-1986) e Wilfred Cantwell Smith (1916-2000).

Esses estudiosos contribuíram de várias formas para a CPR, mesmo que alguns estivessem motivados religiosamente em seus trabalhos científicos, como Mensching e Eliade, quando "ambos tinham uma mensagem e desejavam mudar seus destinatários/receptores/beneficiários existencialmente por meio de seus trabalhos científicos religiosos" (TWORUSCHKA, 2013, p. 580).

Apesar disso, Mensching e Eliade contribuíram para a CRA de diversas formas, destacando, por meio de seus estudos comparativos das religiões, resultados práticos e aplicabilidade em termos de diálogo, tolerância e valores culturais.

Mensching ganhou notoriedade na CRA, sobretudo por causa dos estudos das suas obras por seu discípulo e sucessor, Klimkeit. Suas principais obras foram "Toleranz und Wahreit in der Religion" (1955), "Der Irrtum in der Religion" (1969) e "Gut und Böse im Glauben der Völker" (1941) e assumiram a perspectiva prática da religião comparada, destacando a tolerância, a crítica e a ética nas religiões, respectivamente (TWORUSCHKA, 2013).

Eliade, segundo Tworuschka (2013), desenvolveu um programa de estudos aplicados com base em um novo humanismo, uma hermenêutica criativa ou uma hermenêutica total, buscando decifrar e explicar o sentido da experiência do sagrado em diferentes tradições religiosas, especialmente as não europeias, como elemento educacional e unificador de valores culturais, culminando no novo humanismo global.

Wilfred Cantwell Smith, como indica Tworuschka (2013), reforça declaradamente que um dos objetivos centrais da CR é o diálogo intercultural. Esse diálogo não pode ser mais impessoal, ou seja, de alguém ou sobre alguém, mas de alguém que observa, estuda, escuta, aprende e fala com/sobre/para o outro de forma recíproca e respeitosa, demonstrando a aplicabilidade dessa disciplina, especialmente nos espaços escolares, pois:

A Ciência da Religião pode desempenhar um papel educacional eminentemente em diálogo e, portanto, tem uma tarefa prática: educar os estudantes que podem realizar o papel de intermediários e intérpretes entre duas tradições religiosas. Isso vale, até mesmo, para as instituições onde a Ciência da Religião é lecionada (TWORUSCHKA, 2013, p. 582).

Esse aspecto educacional, singular no mundo hodierno, vem ocorrendo no Brasil desde a década de 1990, com as Licenciaturas em CR, mas não se tem conhecimento dessa experiência em outros lugares no mundo. As licenciaturas em $\mathrm{CR}$, em tese, foram criadas com o objetivo de atender às demandas educa- 
cionais atuais do ER, pois, até então, as experiências praticadas nas escolas (confessional e interconfessional) eram incompatíveis com a laicidade do Estado e, consequentemente, implicadores dos princípios constitucionais.

Essa compreensão, que aproxima CR, formação de professores e ER, só foi possível mediante a mobilização política de movimentos ligados ou não à religião e ao seu possível estudo na escola, ainda fortemente marcado por disputas e interesses de vários lados (SANTOS, 2017). Após alguns anos de licenciatura e muitos de pós-graduação, a ciência pura (CR) e a aplicada (CPR ou CRA) da religião passaram a ser compreendidas e defendidas epistemologicamente nos espaços acadêmicos e educacionais.

É somente a partir da década de 1990 que se retoma a perspectiva de área de formação docente de ER é Ciência da Religião. A consolidação dessa concepção dá-se a partir de 2006, no $9^{\circ}$ Seminário Nacional de Capacitação Profissional para o Ensino Religioso, realizado pelo FONAPER em parceria com a PUCSP (PIEPER, 2017, p. 136).

Do referido seminário, a primeira obra que reuniu várias conferências proferidas no evento, além de pesquisas sobre CR, formação docente e ER, foi o livro "Ensino religioso e formação docente: ciências da religião e ensino religioso em diálogo", organizado por Luzia Sena (2006).

Também destacam-se as obras: "Ensino religioso: construção de uma proposta", de João Décio Passos (2007), e "Religião \& educação: da ciência da religião ao ensino religioso", de Afonso Maria Ligorio Soares (2010). Em ambos, há confirmação de que a CR é a disciplina acadêmica que assegura base epistemológica para a formação desses professores e a sua aplicação no ER nas escolas públicas, rompendo, assim, com velhos modelos e práticas que colocavam em evidência a laicidade do Estado. Logo:

A compreensão da religião como objeto do ensino religioso está compreendida como o estudo das diferentes manifestações que interferem na formação da sociedade e que são estudadas pela Ciência da Religião no espaço acadêmico, subsidia a transposição didática para o cotidiano da sala de aula que favorecerá aos estudantes da educação básica a compreensão da cultura das diferentes comunidades que formam o país (JUNQUEIRA, 2013, p. 609).

Essas definições, constatadas nas produções teórico-metodológicas, têm provocado ressonâncias positivas na educação. Um grande exemplo disso foi a aprovação da Base Nacional Comum Curricular (BNCC), em 15 de dezembro de 2017, pelo Ministério da Educação (MEC), e a referência à CR como área de conhecimento notável para a prática do ER (BRASIL, 2017a). 
As implicações perpassam todos os espaços de atuação da CR e podem ser traduzidas de diversas formas, assim pontuadas por alguns trabalhos que indicam certo desconhecimento, apropriação e discussão teórico-metodológica da própria disciplina, especialmente no contexto internacional, bem como a quase ausência de professores formadores com graduação em CR (COSTA; STERN, 2017), o que possibilita o forte caráter teológico identificado em pesquisas e avaliações de alguns cursos de graduação e pós-graduação, por exemplo (SANTOS, 2014).

Assim, é preciso dispensar esforços no sentido de se conhecer melhor a história dessa área de conhecimento, apropriando-se dos seus aportes epistemológicos próprios desenvolvidos na sua estrutura interna em estudos histórico e sistemático, e não mais buscá-los na Teologia e nas subdisciplinas de outras áreas, pois o que se tem observado é a dispersão ou a diluição do estudo sobre religiões, implicando, assim, a ausência de identidade e a falta de reconhecimento científico dessa disciplina no país.

\section{Formação de professores e Ensino Religioso}

O diálogo estabelecido entre CR e CPR, ou CRA à educação, torna possível o ER e se refere a ele próprio, que, desde a última alteração (Lei no 9.475/1997) no artigo 33 da Lei de Diretrizes e Bases da Educação Nacional (LDB), assumiu no dispositivo legal a compreensão de área de conhecimento (BRASIL, 1998; 2010a; 2010b), e que, com a aprovação do ER na BNCC (BRASIL, 2017a), espera-se a definição pelo Conselho Nacional de Educação (CNE) se receberá o tratamento de área de conhecimento ou de componente curricular das Ciências Humanas (BRASIL, 2017a; BRASIL, 2017b).

Essa definição ainda em suspensão pelo CNE ao ER na BNCC evidencia a distância entre CR e CRA, que traduz a velha separação da ciência iluminista entre ciência pura e prática/aplicada, pois, além do desconhecimento dessa disciplina acadêmica, assim como da sua aplicação, o que realça a sua relevância social para uma educação pública e laica, a CR ainda sofre impactos da sua irmã mais velha, a Teologia.

A CR, nesses quase dois séculos de emancipação enquanto disciplina acadêmica, ainda está fortemente marcada pelos interesses confessionais das Teologias cristãs, haja vista o processo histórico de formação sociocultural do país e também a imagem construída sobre a CR de que ela, em seu estatuto científico, induziria a perda da fé ou a descrença nos alunos.

Essa ilusão é facilmente descontruída, pois os alunos estão submetidos quase todos os dias ao estudo de outras ciências, as quais, como tais, não assumem os pressupostos da fé e da crença religiosa, mas nem por isso deixam de tê-las; a CR é um empreendimento empírico, alocada na grande área das Ciências Humanas, seguindo assim os princípios e os pressupostos que competem a toda e qualquer ciência, o que não exclui também os seus limites. 
Os fatos religiosos são estudados dentro dos limites observáveis e constatáveis na materialidade sociocultural, considerando suas influências, suas determinações e seus simbolismos, marcados pela diversidade de sentidos e significados.

As religiões e as espiritualidades, assim como a negação de uma realidade sobre-humana, estão presentes e fazem muita, para não dizer toda, diferença na vida/existência humana, marcando-a de diversas formas. Assim, a relevância social dessa disciplina acadêmica estaria associada em auxiliar os alunos a compreender a presença das religiões e das espiritualidades no seu próprio contexto e a sua negação, de maneira que não prescindisse à sua própria realidade, para a qual devem ser preparados a encarar do melhor modo possível.

A CR não nega os discursos e as experiências sobre-humanos das religiões e das espiritualidades; pelo contrário, ressalta, a partir daquilo que pode ser observado e constado, como são importantes para os que neles acreditam, por isso cada discurso e experiência devem estar restritos a eles, pois cada grupo é livre para expressar e viver a sua liberdade religiosa.

Assim, a CR não se priva de mostrar quando esses limites são extrapolados ou são usados para outros fins que não sejam humanos, como ocorreu no passado; erros que atravessaram várias religiões com interpretações ou compreensões equivocadas, geralmente não refletidas que serviram de base para justificar e legitimar muitos crimes, violências e várias formas de discriminação que ainda hoje precisam ser combatidas na escola e na sociedade como um todo.

A CR é mais que uma aliada do Estado brasileiro, é uma parceira que vem crescendo na educação e na escola pública, auxiliando os alunos na sua formação integral e cidadã, assim como contribuindo sobremaneira para o respeito das liberdades individuais e coletivas.

Entre os licenciados em CR no Brasil, não há hesitações de que ela seja a área de conhecimento das Ciências Humanas que assegura o ER como componente curricular na EB. Um grande passo foi dado com a aprovação do ER na BNCC, assim compreendida como um "documento de caráter normativo que define o conjunto orgânico e progressivo de aprendizagens essenciais que todos os alunos devem desenvolver ao longo das etapas e modalidades da Educação Básica” (BRASIL, 2017a, p. 7), orientada por princípios éticos, políticos e estéticos que objetivam a formação humana integral e a construção de uma sociedade justa, democrática e inclusiva (BRASIL, 1996).

Para isso, a BNCC estabeleceu seu foco no desenvolvimento de competências gerais e específicas para cada área/componente curricular, somado ao compromisso com a educação integral e ao pacto de cooperação para igualdade, diversidade e equidade entre os entes federados, visando, dessa forma, a uma educação em direitos humanos, aliada à justiça social e à preservação ambiental.

Nesse sentido, o ER é parte integrante desse processo e possui os seguintes objetivos: 
a) Proporcionar a aprendizagem dos conhecimentos religiosos, culturais e estéticos, a partir das manifestações religiosas percebidas na realidade dos educandos;

b) Propiciar conhecimentos sobre o direito à liberdade de consciência e de crença, no constante propósito de promoção dos direitos humanos;

c) Desenvolver competências e habilidades que contribuam para o diálogo entre perspectivas religiosas e seculares de vida, exercitando o respeito à liberdade de concepções e o pluralismo de ideais, de acordo com a Constituição Federal;

d) Contribuir para que os educandos construam seus sentidos pessoais de vida a partir de valores, princípios éticos e da cidadania (BRASIL, 2017a, p. 434).

É bom ressaltar um aspecto já anunciado e que às vezes não aparece nas discussões educacionais sobre o ER, sobre quem seria o profissional devidamente habilitado para desenvolver as competências específicas propostas para esse componente curricular. Esse profissional, comprometido com uma educação social e laica, não é mais um representante de uma confissão religiosa, nem aquele que foge aos requisitos para os profissionais da educação previstos no artigo 62 da LDB (BRASIL, 1996), mas um cientista das religiões, um profissional legalmente licenciado em CR, com formação teórico-metodológica e pedagógica (SANTOS; SEIBT, 2014; SANTOS, 2014).

Esse docente, durante a sua formação inicial em CR, e não em Teologia (um especialista da sua própria confissão), é orientado de forma não normativa ao estudo histórico e sistemático das religiões empiricamente, o que não exclui espiritualidades, filosofias de vida seculares ou não, considerando suas diferentes manifestações e seus contextos socioculturais, assim como seus efeitos produzidos. Nesse processo, o cientista das religiões não toma partido, pois adota o ideal da neutralidade, sem questionar a "verdade" ou "qualidade" das religiões (USARSKI, 2006).

Dessa forma, o licenciado em CR é o profissional devidamente qualificado para isso, que viabiliza a CRA na escola por meio do ER, o qual, conforme consta na BNCC, possui as seguintes competências específicas:

1. Conhecer os aspectos estruturantes das diferentes tradições/ movimentos religiosos e filosofias de vida, a partir de pressupostos científicos, filosóficos, estéticos e éticos.

2. Compreender, valorizar e respeitar as manifestações religiosas e filosofias de vida, suas experiências e saberes, em diferentes tempos, espaços e territórios;

3. Reconhecer e cuidar de si, do outro, da coletividade e da natureza, enquanto expressão do valor da vida;

4. Conviver com a diversidade de crenças, pensamentos, convicções, modos de ser e viver; 
5. Analisar as relações entre as tradições religiosas e os campos da cultura, da política, da economia, da saúde, da ciência, da tecnologia e do meio ambiente;

6. Debater, problematizar e posicionar-se frente aos discursos e práticas de intolerância, discriminação e violência de cunho religioso, de modo a assegurar os direitos humanos no constante exercício da cidadania e da cultura da paz (BRASIL, 2017a, p. 437).

Essas competências mobilizam conhecimentos concretos sobre as religiões, e não para as religiões, que precisam ser previamente adequados ao nível cognitivo dos alunos (SANTOS, 2018b) e resultam em práticas e atitudes socioemocionais para "resolver demandas complexas da vida cotidiana, do pleno exercício da cidadania e do mundo do trabalho" (BRASIL, 2017a, p. 13).

Com certeza, as religiões demandam essa necessidade, e o Estado, quando assegura a permanência desse profissional na educação, contribui socialmente para isso, tendo em vista os casos de intolerância religiosa, conflitos religiosos e posturas discriminatórias produzidos historicamente e que vêm sendo retroalimentados em vários espaços públicos.

Recentemente, o MEC estabeleceu uma Subcomissão para assessorar a Comissão instituída no âmbito da Câmara de Educação Superior (CES) e analisar a necessidade de estabelecer Diretrizes Curriculares Nacionais do curso de graduação em Ciência da Religião ${ }^{2}$.

Nesse sentido, o MEC/CNE e o Conselho Pleno (CP) apresentaram o texto referência para a audiência pública sobre as Diretrizes Curriculares Nacionais (DCN) para o curso de graduação em Ciência da Religião - Minuta de Parecer e Projeto de Resolução, em setembro de 2018, em Brasília (BRASIL, 2018d).

Após isso, em 28 de dezembro de 2018, foi homologado o Parecer CNE/ CP no 12 (BRASIL, 2018a) e a Resolução no 5 (BRASIL, 2018b), que definem as DCN para o curso de graduação em CR.

Segundo a referida Resolução, em seu artigo $2^{\circ}$, "O curso de licenciatura em Ciências da Religião constitui-se como habilitação em nível de formação inicial para o exercício da docência do Ensino Religioso na Educação Básica" (BRASIL, 2018b), reconhecendo, assim, a CR como disciplina de referência para a formação inicial de professores de ER no Brasil, algo que já vinha ocorrendo em vários Estados desde 1996.

É bom destacar também outros aspectos relevantes da Resolução que prezam pela formação humana a partir dessa ciência, retificando todo empreendimento confessional nas escolas públicas:

Art. $6^{\circ} \mathrm{O}$ curso de licenciatura em Ciências da Religião, respeitada a diversidade nacional e a autonomia pedagógica das instituições, estrutura-se nos seguintes núcleos: I - Núcleo de formação geral, que articulará: [...] c) Formação inclusiva, assegurada pelo 
estudo das relações entre educação e diversidade, direitos humanos e cidadania, educação ambiental, educação especial, relações étnicas e raciais, de gênero, de geração e de classes sociais, língua brasileira de sinais (LIBRAS), em conformidade com o $\int 2^{\circ}$ do artigo 13 da Resolução CNE/CP n ${ }^{\circ}$ 2, de $1^{\circ}$ de julho de 2015. II - Núcleo de formação específica, que articulará: a) Formação específica em Ciências da Religião, assegurada por meio da/do: 1. Fundamentação histórica e epistemológica da área de Ciências da Religião; 2. Apropriação dos aspectos estruturantes das matrizes, tradições e movimentos religiosos de origens africanas, indígenas, asiáticas, orientais e ocidentais, considerados em sua multiplicidade de elementos (linguagem religiosa, símbolos, ritos, espaços, territórios, mitos, divindade(s), crenças, doutrinas, textos orais e escritos, ideias sobre existência e imortalidade, princípios e valores éticos); 3. Estudo e pesquisa de correntes filosóficas e movimentos socioculturais não religiosos; 4. Estudo sistemático das religiões, o que inclui abordagens comparativas, classificatórias e reflexivas, as quais visam a interface com temáticas transversais à sociedade e à cultura, tais como: religião e sociedade, religião e política, religião e economia, religião e mídia, religião e ciência, religião e arte, religião e violência, religião e sexualidade, religião e natureza, dentre outros; 5. Desenvolvimento e aplicação dos conhecimentos específicos das Ciências da Religião em espaços formais e não formais de ensino, na construção de processos de aprendizagem crítica e transdisciplinar sobre os fenômenos religiosos, a fim de subsidiar o diálogo inter-religioso, a interculturalidade, os direitos humanos e da cultura da paz. b) Formação específica em Ensino Religioso, assegurada por meio da: 1. Apropriação dos fundamentos históricos, epistemológicos e metodológicos do Ensino Religioso de natureza não confessional e não proselitista, necessários à sua docência em diferentes etapas e modalidades da Educação Básica; [...] (BRASIL, 2018b, p. 2-3).

Além desses dois núcleos, o da formação geral e o da formação específica, há um terceiro, o de estudos integradores, que destaca o enriquecimento curricular por meio de várias atividades de caráter científico e cultural, práticas, mobilidade estudantil e de comunicação e expressão.

Nisso, apesar das recentes mudanças que alcançam a educação, a escola e seus pares, o MEC pela primeira vez tratou o ER e o seu profissional como os demais, atendendo aos dispositivos, princípios e pressupostos legais que regem o sistema educacional brasileiro.

Mas isso não significa que as inconsistências e as divergências deixem ou parem de existir, pois a ausência de licenciaturas em CR na maioria dos Estados é uma realidade, sem contar os problemas presentes em várias legislações estaduais; entretanto, é visível a concretização desse avanço fundamental na área de formação e a sua aplicação com a publicação da BNCC e da referida Resolução. 


\section{Considerações finais}

Levando em consideração o que aqui foi abordado, o legado social promovido pelo cientista das religiões na educação e na escola, que tem o ER, principalmente, como seu campo de atuação profissional, pode ser muito bem inserido e aproveitado no campo educacional de uma forma mais ampla.

São notórias várias experiências nas escolas em que a CRA vem assegurando e tornando o ER um componente curricular que promove impacto social e humano (SANTOS, 2018a).

Esse impacto só pode ser assegurado quando observados os dispositivos legais que exigem a formação devida na área de atuação profissional, sem a qual não há o que se esperar, pois isso é uma exigência primordial para todo e qualquer profissional.

A CR é uma área de conhecimento como as demais, possuindo objeto, teoria e métodos próprios, o que não a impede de utilizar e compartilhar de outros. Esse aspecto não a torna menos importante, não a impede de ter seu devido espaço acadêmico e aplicado nem inviabiliza seu desdobramento em CRA (STERN; COSTA, 2018).

Toda ciência produz conhecimentos indispensáveis à sociedade que são oriundos de recursos públicos em sua maioria e, como tal, precisam produzir resultados que possam também ser aproveitados em benefícios dela. É exatamente esse aspecto que foi destacado por Junqueira (2013, p. 614), quando se refere à aplicação de qualquer ciência. Para ele, a CR torna possível o ER nos espaços públicos e privados, pois:

[...] cada componente curricular é orientado para que os estudantes dominem as diferentes linguagens, compreendam os fenômenos, sejam físicos ou sociais, construam argumentações para elaborar propostas e enfrentem as diversas situações de suas vidas (JUNQUEIRA, 2013, p. 614).

Essa orientação, destacada pelo autor, é central na BNCC cujo foco está no desenvolvimento de competências, tendo em vista uma educação integral que respeite o tempo e a maneira de aprendizagem dos alunos. Para isso:

Requer o desenvolvimento de competências para aprender a aprender, saber lidar com a informação cada vez mais disponível, atuar com discernimento e responsabilidade nos contextos das culturas digitais, aplicar conhecimentos para resolver problemas, ter autonomia para tomar decisões, ser proativo para identificar os dados de uma situação e buscar soluções, conviver e aprender com as diferenças e as diversidades (BRASIL, 2017a, p. 14). 
Esses direitos previstos aos alunos só podem ser previamente assegurados mediante a formação inicial de seus professores nos seus respectivos componentes curriculares; logo, o profissional de ER não foge a essa regra.

Nesse sentido, a CR cumpre esse papel (BRASIL, 2017a, 2018a, 2018b) e, embora não seja ofertada de forma regular em todos os Estados brasileiros, é adotada como ciência de referência para a formação inicial e aplicação no ER, dispondo de epistemologias, métodos e abordagens próprias, atendendo, nesse aspecto, ao estudo cientificamente sobre religiões nas escolas públicas e privadas também.

Por sua vez, as religiões como objeto dessa disciplina acadêmica não são um dado estranho nem ausente na realidade como um todo; pelo contrário, ainda continuam ocupando espaços privilegiados em toda e qualquer elaboração humana.

Dessa forma, compreender essa dinâmica criada pelas religiões, ou melhor, pelos humanos, é mais do que orientar como as coisas são ou como poderiam ser, é explicar por que as coisas continuam do jeito que estão.

Recebido em: 08/04/2019

Revisado pelo autor em: 10/05/2019 Aceito para publicação em: 21/05/2019

\section{Notas}

1 Doutorando em Ciência da Religião pela Pontifícia Universidade Católica de São Paulo. Professor de Ensino Religioso na rede municipal de Belém e na rede estadual do Pará. Bolsista da CAPES. E-mail: professorcr@hotmail.com

2 Subcomissão estabelecida pela Portaria CNE/CES nº 6, de 26 abril de 2018 (BRASIL, 2018c).

\section{Referências}

BRANDÃO, Carlos Rodrigues. O que é educação? São Paulo: Brasiliense, 2007. BRASIL. Lei $n^{\circ}$ 9.394, de 20 de dezembro de 1996. Estabelece as diretrizes e bases da educação nacional. Diário Oficial [da] União, Brasilia, DF, 23 dez. 1996. Disponível em: http://www.planalto.gov.br/ccivil_03/leis/19394.htm. Acesso em: 25 jan. 2019.

. Lei no 9.475, de 22 de julho de 1997. Dá nova redação ao art. 33 da Lei no 9.394, de 20 de dezembro de 1996, que estabelece as diretrizes e bases da educação nacional. Diário Oficial [da] União, Brasília, DF, 23 jul. 1997. Disponível em: http://www.planalto.gov.br/ccivil_03/leis/L9475.htm. Acesso em: 25 jan. 2019.

. Resolução n ${ }^{\circ}$ 02, de 7 de abril de 1998. Institui as Diretrizes Curriculares Nacionais para o Ensino Fundamental. Diário Oficial [da] União, Brasília, DF, 15 abr. 1998. Disponível em: http://portal.mec.gov.br/dmdocuments/ resolucao_ceb_0298.pdf. Acesso em: 25 jan. 2019. 
. Resolução no 04, de 13 de julho de 2010. Define Diretrizes Curriculares Nacionais Gerais para a Educação Básica. Diário Oficial [da] União, Brasília, DF, 14 jul. 2010a. Disponível em: http://portal.mec.gov.br/dmdocuments/rceb007_10.pdf. Acesso em: 25 jan. 2019.

. Resolução no 07, de 14 de dezembro de 2010. Fixa Diretrizes Curriculares Nacionais para o Ensino Fundamental de 9 (nove) anos. Diário Oficial [da] União, Brasília, DF, 15 dez. 2010b. Disponível em: http://portal.mec.gov. br/dmdocuments/rceb004_10.pdf. Acesso em: 25 jan. 2019.

Base nacional comum curricular. Brasília: MEC, 2017a. Disponível em: http://basenacionalcomum.mec.gov.br/images/BNCC_EI_EF_110518_ versaofinal_site.pdf. Acesso em: 25 jan. 2019.

. Resolução $n^{\circ} 2$, de 22 de dezembro de 2017. Institui e orienta a implantação da Base Nacional Comum Curricular, a ser respeitada obrigatoriamente ao longo das etapas e respectivas modalidades no âmbito da Educação Básica. Diário Oficial [da] União, Brasília, DF, 22 dez. 2017b. Disponível em: http://portal.mec.gov.br/index.php?option=com_docman\&view =download\&alias=79631-rcp002-17-pdf\&category_slug=dezembro-2017-pdf\&Itemid=30192. Acesso em: 25 jan. 2019.

. Parecer CNE/CP no 12, de 2 out. 2018. Diretrizes Curriculares Nacionais para os cursos de licenciatura em Ciências da Religião. Parecer homologado pela Portaria no 1.403. Diário Oficial [da] União, Brasília, DF, 28 dez. 2018a. Disponível em: http://portal.mec.gov.br/index.php?option=com_do$\mathrm{cman \& view}=$ download\&alias=99971 - pcp012-18\&category_slug=outubro-2018-pdf-1\&Itemid=30192. Acesso em: 15 jan. 2019.

Resolução no 5, de 28 de dezembro de 2018. Institui as Diretrizes Curriculares Nacionais para o curso de licenciatura em Ciências da Religião e dá outras providências. Diário Oficial [da] União, Brasília, DF, 31 dez. 2018b. Disponível em: http:/ / abmes.org.br/arquivos/legislacoes/Res-CP-CNE-005-2018-12-28.pdf. Acesso em: 25 jan. 2019.

. Resolução n ${ }^{\circ} 1$, de 6 de abril de 2018. Estabelece diretrizes e normas para a oferta dos cursos de pós-graduação lato sensu denominados cursos de especialização, no âmbito do Sistema Federal de Educação Superior, conforme prevê o Art. 39, S $3^{\circ}$, da Lei no 9.394/1996, e dá outras providências. Diário Oficial [da] União, Brasília, DF, 9 abr. 2018c. Disponível em: http:/ /portal.mec.gov.br/ docman/abril-2018-pdf/85591-rces001-18/file. Acesso em: 25 jan. 2019.

Ministério da Educação. Conselho Nacional de Educação. Conselho Pleno. Texto referência para a audiência pública sobre as Diretrizes Curriculares Nacionais para o curso de graduação em Ciência(s) da(s) 
Religão(ões): Minuta de Parecer e Projeto de Resolução. Brasília, DF, set. 2018d. Disponível em: https://ipfer.com.br/wp-content/uploads/2018/09/ texto_referencia_DCN_ciencias_da_religiao.pdf. Acesso em: 15 jan. 2019.

COSTA, Matheus; STERN, Fábio. Metodologias desenvolvidas pela genealogia intelectual da ciência da religião. Sacrilegens, UFJF, v. 14, n. 1, p. 70-89, jan./jun. 2017. Disponível em: http://www.ufff.br/sacrilegens/files/2017/12/14-1-6.pdf. Acesso em: 25 jan. 2019.

GRESCHAT, Hans-Jürgen. O que é ciência da religião. São Paulo: Paulinas, 2005.

JUNQUEIRA, Sergio. Ciência da religião aplicada ao ensino religioso. In: PASSOS, João Décio; USARSKI, Frank (org.). Compêndio de ciência da religião. São Paulo: Paulinas/Paulus, 2013. p. 603-614.

PASSOS, João Décio. Ensino religioso: construção de uma proposta. São Paulo: Paulinas, 2007.

PASSOS, João Décio; USARSKI, Frank (org.). Compêndio de ciência da religião. São Paulo: Paulinas/Paulus, 2013.

PIEPER, Frederico. Ciência(s) da(s) religião(ões). In: JUNQUEIRA, Sérgio; BRANDENBURG, Laude; KLEIN, Remi (org.). Compêndio de ensino religioso. São Leopoldo: Sinodal; Petrópolis: Vozes, 2017. p. 131-139.

SANTOS, Rodrigo Oliveira dos; SEIBT, Cezar Luis. Ciências da religião e o ensino religioso na Amazônia. Revista Pistis \& Praxis: Teologia e Pastoral, Curitiba, v. 6, n. 2, p. 373-397, maio/ago. 2014. Disponível em: https://periodicos. pucpr.br/index.php/pistispraxis/article/view/5584. Acesso em: 25 jan. 2019.

SANTOS, Rodrigo Oliveira dos. As abordagens da morte no currículo de formação inicial de professores de ensino religioso no Pará. 2014. Dissertação (Mestrado em Educação) - Programa de Pós-Graduação em Educação, UFPA, Belém, 2014.

. Movimento institucional das pessoas favoráveis e contrárias ao ensino religioso. In: JUNQUEIRA, Sérgio; BRANDENBURG, Laude; KLEIN, Remi (org.). Compêndio de ensino religioso. São Leopoldo: Sinodal; Petrópolis: Vozes, 2017. p. 50-62.

. Ciência da religião aplicada ao ensino religioso. In: STERN, Fábio; COSTA, Matheus Oliva da (org.). Ciência da religião aplicada: ensaios pela autonomia e aplicação profissional [recurso eletrônico]. Porto Alegre: Editora Fi, 2018a. p. 161-181. 
- Ciência da religião e transposição didática: compreensão e impacto no ensino religioso. PLURA, Revista de Estudos de Religião, v. 9, n. 1, p. 30-55, 2018b.

SENA, Luzia (org.). Ensino religioso e formação docente: ciências da religião e ensino religioso em diálogo. São Paulo: Paulinas, 2006.

SOARES, Afonso Maria Ligorio. Religião \& educação: da ciência da religião ao ensino religioso. São Paulo: Paulinas, 2010.

STERN, Fábio; COSTA, Matheus Oliva da (org.). Ciência da religião aplicada: ensaios pela autonomia e aplicação profissional. Porto Alegre: Editora Fi, 2018.

TWORUSCHKA, Udo. Ciência prática da religião. In: PASSOS, João Décio; USARSKI, Frank (org.). Compêndio de ciência da religião. São Paulo: Paulinas/Paulus, 2013. p. 577-588.

USARSKI, Frank. Constituintes da ciência da religião: cinco ensaios em prol de uma disciplina autônoma. São Paulo: Paulinas, 2006.

. Historia da ciência da religião. In: PASSOS, João Décio; USARSKI, Frank (org.). Compêndio de ciência da religião. São Paulo: Paulinas/Paulus, 2013. p. 51-61. 